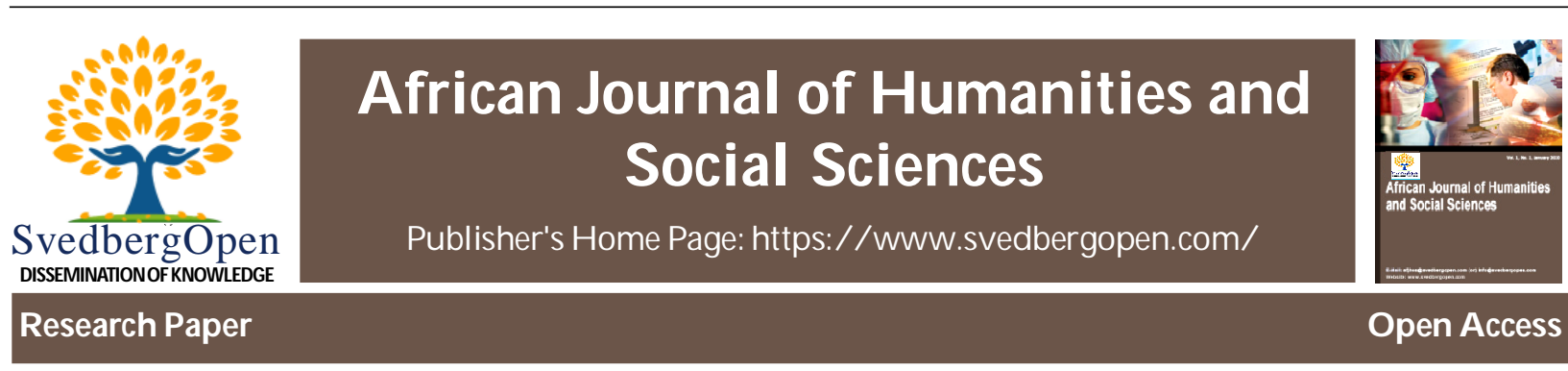

\title{
Transcendental Theology for Non-Believers
}

\author{
Michael Kowalik ${ }^{1 *}$ \\ ${ }^{1}$ Independent Researcher, Melbourne, VIC 3000, Australia. E-mail: mkowalik@gmx.net
}

\section{Article Info}

Volume 2, Issue 1, February 2022

Received : 23 March 2021

Accepted : 18 December 2021

Published : 01 February 2022

doi: 10.51483/AFJHSS.2.1.2022.30-37

\begin{abstract}
Pope Benedict XVI argued that it is "necessary and reasonable to raise the question of God through the use of reason" and to understand "theology, as inquiry into the rationality of faith." (Ratzinger, 2006) The idea that faith per se can be reconciled with rationality per se presents a delicate analytical task for philosophy of religion, to consistently ground a belief system that is regarded by non-believers as inherently ungrounded and inconsistent, without negating any grounding postulates internal to the dogma. Focusing on Abrahamic theism, with special emphasis on Christianity, I interpret the Biblical narrative as a symbolic representation of a universal normative structure grounded in social ontology and the value-commitments intrinsic to agency.
\end{abstract}

Keywords: Christianity, Judaism, Metaethics, Social Ontology, Transcendental Theology

(C) 2022 Michael Kowalik. This is an open access article under the CC BY license (https: //creativecommons.org/licenses/by/4.0/), which permits unrestricted use, distribution, and reproduction in any medium, provided you give appropriate credit to the original author(s) and the source, provide a link to the Creative Commons license, and indicate if changes were made.

\section{Introduction}

Religious ideas were the primary mode of cultural expression throughout human history. Since the Palaeolithic period "the history of religious ideas and beliefs is one with the history of civilization." (Eliade, 1978) The last two centuries of the Common Era were exceptional in that regard, witnessing a protracted decline of religious thought and the rise of secularism, but the dichotomy of religion vis a vis secularism may rest on a mischaracterization of the latter. It is not a trivial matter that the emergence of secularism was a uniquely Christian phenomenon. According to Altizer (2003), the ending of Christianity as the overtly dominant force in Europe "impacted upon the world as a whole, initiating a new and comprehensive secularism, yet that secularism can be and has been understood as being in essential continuity with the Christendom that generated it". Thousands of years of ritual conditioning and sacramental trauma cannot be erased merely by not believing in God. The contemporary secular mindset is still infused with Christian symbolism and conscience, which were 'merely secularized', reconfigured by means of reason into humanist ethics. I argue that religious ideas are not just a contingent result of irrational imagination but, in general, symbolize something fundamental to what human beings have intrinsically in common. The specific

\footnotetext{
* Corresponding author: Michael Kowalik, Independent Researcher, Melbourne, VIC 3000, Australia.

E-mail: mkowalik@gmx.net
} 
aim of this study is to demonstrate that Abrahamic theism, and Christianity in particular, can be grounded a priori in the constitutive conditions of agency without negating any of the canonical dogmas: transcendental theology.

\section{On Faith}

Religion typically involves a commitment to a dogma: a set of alleged truths that every adherent of a particular religion believes 'as true', and this belief constitutes the Religion. The general epistemic schema of religious belief is therefore logically circular: conviction about the truth-value of the object of belief obtains, at least in part, in virtue of it being believed. The primary obstacle to reconciliation of religion with reason is therefore the very question of faith. The meaning of faith per se must be sufficiently rational to remain open to logically nonregressive epistemic validation, or else, its epistemic circularity must be somehow grounded in realist ontology.

The Greek word Pistis is one of the key terms in Christian theology, is routinely translated as Faith, although the meaning of Pistis is both broader and epistemically weaker than the contemporary idea of religious faith, that of 'strong belief in the doctrines of religion, based on spiritual conviction rather than proof' '. In Greek mythology, Pistis was understood as the personification of good faith, trust and honesty (Liddell and Robert, 1940), but the Christian tradition is believed to have drawn on a more recent, discursive sense of the term: to be open to persuasion by the evidence of Reason/Logos (Hay, 1989; Danker, 2000). The state of permanent openness to persuasion without assuming that our knowledge is already complete, already perfect, is still consistent with showing good faith in regard to someone else's point of view, rendering Pistis a state of intellectual or perhaps spiritual openness to something beyond ourselves. I suggest that the older definition of Pistis, understood as having good faith in relation to others, is the most rational approximation of the intended meaning (Cf. Titus 2:10).

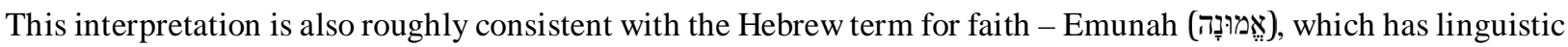
connotations of faithfulness and discerning trust: an active principle, akin to giving support to another.

A discourse necessarily involves reciprocal commitment to generate meaning, to be understood and to understand one another in good faith. This active aspect was extensively theorized by Jürgen Habermas and Karl-Otto Apel in relation to the principle of Discourse Ethics. The central idea of Discourse Ethics is that when we speak or respond in a meaningful way to another we are affirming certain symmetry about meaning, whose value or truth-aptness consists solely in being rationally held in common. According to Apel, by verbalizing any claim we are implicitly recognizing our interlocutor as a being capable of rationally responding to our claim and we are inviting them to do so: "The logical justification for our thought" therefore commits us to "understand arguments critically" and to "mutually recognize each other as participants with equal rights in the discussion" (Apel, 1996, 29). This "consensual-communicative rationality [is] presupposed already in the use of language (and, therefore, in thought itself)..." (Ibid.210-11). It follows that communicating in good faith in order to accomplish reciprocal affinity of meaning - a communion of Logos - is the grounding principle of all meaning, of thought, and therefore of our personhood. Our will to exist is then inseparable from the need for meaning, manifested in practice as an inclination or 'thirst' for intersubjective communion of Logos.

The idea of 'good faith' can be readily extended to spirituality, as openness to the communion of human consciousness with God ${ }^{2}$. This would in turn imply a degree of spiritual affinity with God. The Christian sacrament of Communion seems to reflect this symbolism. Following the example of Discourse Ethics, the concept of faith as simply 'openness to Spirit' may not fully capture the essence of the term. In addition to openness, a special inclination or thirst for spiritual communion may be required. There are indeed instances in the can on stressing the importance of such an inclination: "ask and you shall receive, seek and you shall find" (Matthew 7:7, Luke 11:9); "Let anyone who is thirsty come to me and drink" (John 7:37). "By this he meant the Spirit", clarifies John.

The proposed interpretation has an important, counterintuitive aspect. A measure of doubt, in the sense of not being committed to the truth of something without careful consideration of reasons, may indeed be an essential part of having good faith, because without doubt we could not give fair consideration to the relevant subjectmatter. By denying the possibility of being mistaken or ignorant about something we would implicitly deny the authority of reason as a normative principle, and therefore negate the possibility of meaning. "The element of doubt is an element in faith itself." (Tillich, 1967, xli) The colloquial understanding of faith as an innate conviction or certainty about the meaning of some aspect of the scripture, or of religious experience, faces another logical impasse. The absolute certainty about anything implies that the believer cannot possibly be mistaken in that

"Faith." Oxford Dictionary of English, 2 ${ }^{\text {nd }}$ Edition, Revised. Oxford University Press, 2005.

Let us for now regard the term 'God' as a placeholder for something yet to be defined. I will attend to this term in the next section. 
respect, which in turn implies that the believer knows everything; any gap in knowledge, anything unknown, could affect the truth of the relevant conviction. It follows that whoever cannot possibly be wrong is necessarily All Knowing and therefore God, but this renders the idea of faith (as an absolute personal knowledge of some aspect of God) inconsistent and potentially blasphemous.

Ultimately, faith implies a value-commitment to the object of faith and as such presupposes good faith with respect to that object; it would be absurd to have faith in something in bad faith. Since good faith entails awareness of uncertainty about our epistemic capacities, it precludes unconditional belief. It is therefore true a priori that faith is not unconditional belief but just 'good faith': openness and thirst towards the object of faith coupled with uncertainty about our understanding of the object.

The practical consequence of taking faith to mean 'good faith in relation to others and to the Spirit', instead of 'certainty of belief about something for which there is no proof', is that it complements rationality instead of being contrary to reason. Faith understood in this way is also the Ethos of Logos, an essential aspect of Logos without which there can be no meaning, thought or personhood. To abandon 'good faith' is to commit oneself to the void, to spiritual non-existence; apart from the unifying power of Logos, which is the ground of all meaning, everything falls apart. For the same reason, if God's nature were contrary to reason it would be empty of meaning, therefore impossible, therefore not God. A fitting name for such an incoherent facsimile of God is, arguably, Evil. God may therefore be the foundation of Logos, the ground of Reason, which is neither identical with Reason nor separate or contrary to Reason. In order to be in communion with the Spirit we must first be in communion with Logos; for this to be possible, good faith is necessary. This characterization of Faith may seem unorthodox, but it was emphatically affirmed by Pope Benedict XVI (Ratzinger, 2006) in his famous Regensburg Lecture: "Not to act reasonably, not to act with Logos, is contrary to the nature of God [which is Logos]." Another way, any epistemic commitment based on inconsistent reasoning is not compatible with Logos. This insight, or perhaps a rediscovery of the true meaning of Faith, may be one of the most important theological shifts in the evolution of Christianity, in principle reconciling Faith with Western rationalism and creating an opening for inter-faith coherence.

\section{The Image of God}

Religions do not spring out of nowhere; they are arguably an expression of cumulative experience symbolically codified as the primary normative structure in every pre-modern communication community. The concept of God is central to this crystallization of meaning. If this concept signifies something in every culture, then what meaning is expressed thereby? Is it possible to understand 'God' in a way that transcends any particular religious dogma?

In order to meaningfully address this question from transcendental perspective one must commit to an idea of divinity that is meaningful not only for cultures that are explicitly theistic but also for those that are agnostic, secular or even ostensibly atheistic. If 'God' is taken to mean an omnipotent, all-knowing person in some transcendent realm (Heaven) who makes demands of his creations and punishes disobedience then many would deny believing in such a person. Some may even argue that this conception of God is a priori refutable. If, on the other hand, 'God' is a hypothetical embodiment or a personification of our highest ideal, our highest value, then, in that sense, we all do believe in God. Disagreements about the belief in God are then focused on what the highest ideal ought to be. Curiously, the more common, apparently simplistic and naive idea of God as a person who has absolute knowledge and power is not as simple and naive on closer examination. Do we not profess to value our rational agency above all else whenever we act on a reason? (Kowalik, 2019) Are we not universally committed to value our capacity to act, our knowledge, insights and wisdom? The personified image of God plausibly signifies the ideal Man, the ultimate agency of which we all possess a trace: the idea of what it means to be human ${ }^{3}$. Do atheists then 'believe' in the idea of personified God? Not explicitly, but implicitly we all do even if we explicitly deny it; the idea of a personified God as the ideal Self is something we always already believe in and worship about ourselves, even if we cannot fully attain it. What counts in favor of this interpretation is that great conquerors of the classical world were regarded as actual gods, whose divine status was 'proven' by their extraordinary agential capacities (Aristotle, 1984, Politics, 1284a).

Personification of the image of God is then not just an idea of 'God as a person' but a value commitment to 'ideal personhood' as God. Another way, we are universally committed to the ideal of personhood as the archetype of all instances of personhood. In religious practice it may be an ideal we strive to realize, maximize, to perfect ourselves

${ }^{3}$ This idea was elaborated by Paul Tillich: "The risk of faith is based on the fact that the unconditional element can become a matter of ultimate concern only if it appears in a concrete embodiment. It can appear in purified and rationalized mythological symbols like God as highest personal being (...) and it is based on a foundation which is not risk: the awareness of the unconditional element in ourselves and our world." (Tillich, 1959, 28). 
and become its faithful image. In God (Logos) we worship the essence of Anthropos as the ground of all meaning, as that which is Sacred, and we thus vicariously personify ourselves as that which we always implicitly idealize. Imago Hominis, the practical reality of man, polluted by error (Hamartia), thus merges with the trace of Imago Dei (Genesis 1:27), the essence of man-made sacred. This essence is arguably not just rational agency (which presupposes consciousness) but the immutable laws of existence, the laws of meaning and the social-reflexivity that ontologically grounds every conscious subject and is exemplified in showing 'good faith' towards others. There may be much more to the idea of God, perhaps even a genuine metaphysical force that touches all being, but there cannot be any less to the image of God than the ideal of personhood.

This way of conceptualizing God has one unprecedented feature; it shifts the religious discourse beyond dogmatic belief into the realm of transcendental evaluation. The coincidence of our highest ideal with the idea of God becomes a matter of Logos, of logical consequence of our shared value-commitments.

\section{Creation: Breaking the Circle}

"In the beginning there was Logos, and Logos was with God, and Logos was God... Through it all things were made, and apart from it nothing was made that has been made. In it was life and the life was the light of humanity." (John 1:1-4).

Intentional action entails the capacity to discriminate between more or less valuable actions, and any distinction of value presupposes an ideal according to which value could be measured. All ideas, the content of thought, all differences and boundaries, are a product of discrimination in favor of what matters and how it matters, which is to say, the world as we know it is a result of cumulative discrimination geared towards an aim that matters above all else. It follows that nothing happens for consciousness without an ideal or standard of value by means of which it is possible to reduce the infinite complexity of being-as-such (or to partition the absolute indifference of All-is-One) to a multiplicity of differentiated and meaningful content. Our intrinsic ideal of personhood is therefore the true creator of the world as we know it.

Conceiving of the ideal of personhood as the sole creative power (God) allows us to retroactively posit the uncreated, the timeless, the indefinite, the unconscious primordial substrate on which The Beginning of the realm of Logos, of time, meaning and consciousness could be inscribed. Such primordial unity is symbolized by Ouroboros, the self-consuming circle of unconscious life, the realm of All-is-One ( $\check{\varepsilon} v \tau$ ò $\pi \propto v)$ where 'nothing matters'. It signifies Nature, the unconscious, perpetual cycle of birth, reproduction and death, which in turn implies animality: instinctive repetition and the absence of transcendence towards an ideal. Animality happens; it does not do. Consciousness, on the other hand, requires meaning, an ideal beyond pure repetition. To be human is to break out of the circle of Nature, to realize the Self in the reflexive relation with other individuals of the same ontological kind and thus become conscious of transcending one's own animality.

Nagel $(1974,436)$ has famously argued that for an organism to have "conscious experience at all means, basically, that there is something it is like to be that organism." Crucially, the phenomenological question of "what it is like to be me' exemplifies a fundamental property of reflexive-consciousness and cannot be meaningfully answered just in terms of 'me', as 'I am me' or 'I am like me', without falling prey to circular reasoning or triviality. "[Self-identity] is certainly a relation formally or logically speaking, but it also holds trivially, it's trivially true of everything..." (Strawson, 2013, 21). It follows that I can be myself only indirectly, socially, by consistently identifying with what I identify others as, insofar as others identify reciprocally. "The individual self will only emerge through the course of social externalization, and can only be stabilized within the network of undamaged relations of mutual recognition" (Habermas, 2003, 34). Phenomenology of self-oriented awareness has thus implicitly demonstrated that reciprocal recognition is an ontological condition of conscious identity and therefore of agency; an idea that may go back to the ancient (albeit uncertain) etymological roots of the word ánthrôpos ('man'): someone who is alike/the likeness of man. This socio-ontological thesis is rigorously developed in Kowalik (2019).

The early-Christian icon from in the Catacombs of St. Domitilla (c. 150-200 AD) may just signify the socioontological grounding of conscious agency (Figure 1). A single fish in the sea is not conscious of itself, it floats in the proverbial unconscious, but two fishes facing one another already symbolize reflexivity: self-awareness via identifying with another being of the same kind. The ideal of personhood thus resolves the Ouroboros, the perpetual cycle of animality submerged in the unconscious, into the reflexive ontology of Anthropos. The Logos cuts across the unconscious, acts as a mirror for the animal to become conscious of itself in the image of another. Being true to the kind, the degree of likeness to the same ideal, is symbolically revealed as the law of conscious existence. This transcendental feature is explicitly formulated in 2 Corinthians (3:18): "And we all, with unveiled 


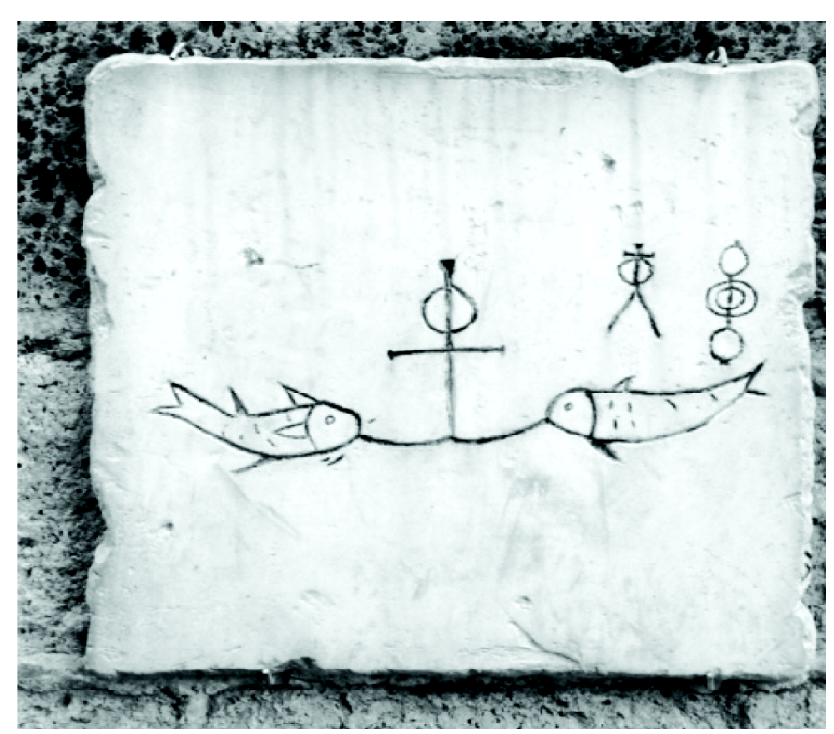

Figure 1: Catacombs of St. Domitilla (c. 150-200 AD)

face, beholding the glory of the Lord, are being transformed into the same image from one degree of glory to another."

\section{On Sin and Repentance}

Hamartia, is an Ancient Greek term typically translated in Christian theology as Sin, meaning an action that in some crucial, metaphysical, moral or spiritual respect is 'wrong'. I consider how the theological idea of Sin, a special kind of wrongdoing, and the associated idea of Repentance can be rationally interpreted.

The Biblical description of sin begins with the Original Sin, a story containing a veiled riddle the solution to which may have profound ontological significance. God commands Adam and Eve not to eat the fruit of 'the tree of the knowledge of good and evil' on pain of death, but they are persuaded by the serpent to disobey the command. The serpent declares that by eating from the tree of knowledge one becomes like God, imbued with moral knowledge. The first subtle twist to this story is that God, by holding Adam and Eve responsible for their actions is implicitly affirming that they already possessed the capacity for discernment of good and evil prior to transgressing the prohibition, otherwise no moral culpability could arise. The second twist to the story is that the wise serpent may have known that Adam and Eve had nothing to gain from disobeying the prohibition, because their capacity for active moral discernment affirmed by Logos was already more potent than any 'received' moral knowledge, which implies dependency. The deception consisted precisely in exchanging the authority for moral discernment mediated by Logos for a nominal declaration of 'moral knowledge' without being mediated by and grounded in Logos, bypassing the filter of rational doubt. We must conclude that the tree of knowledge signifies the capacity for choice between false knowledge, standing apart from Logos, and the truth, which is necessarily bound by Logos. The presence of this tree in the Garden of Eden, together with the snake inhabiting it, is an embodiment of error imitating knowledge, the consciousness of which marks out the choice between Logos and Chaos, creation vs. Annihilation. By consuming its fruit, Adam and Eve have performatively committed themselves to exile from the realm of Logos, into the sphere of personal convictions and the irreconcilable interpersonal conflict, vulnerability, fear and resentment that such convictions entail. The event of being 'exiled by God' is then not an additional action but an inescapable ontological consequence of the erroneous choice that Adam and Eve have themselves made. It is a choice that always remains universally present; we are existentially compelled to make that choice every moment, as it lies at the core of every intention. When we ignore it, when we do not take it seriously, we fall into ontological error and diminish our humanity.

It is of little value to acknowledge that some action is wrong without understanding why it is wrong. Only when we understand the principle of wrongdoing we are capable of initiating a genuine change of mind, that is, we must be able to comprehend what we believe to be wrong not just as being 'wrong' dogmatically but as a principle that 
is comprehensible and consistently motivating 'for us'. As Goethe writes in "Dichtung und Wahrheit", 2.8: "we cannot see a mistake until we are free of it." In essence, the capacity to discern right from wrong requires consistent evaluation. The associated idea of Repentance is then just a change of attitude from affirmation of error to affirmation of that which is true, correct or right; the relevant transgression may ultimately be a transgression against ourselves, against our existence as Imago Hominis, the Anthropos, which, when free from error, is perhaps coincidental with Imago Dei. Sin understood in this way is not just a moral but ontological principle, an erroneous attitude of implicit denial of what we essentially are and thus negates our human essence: Logos. To deny Logos within us is to deny ourselves, to renounce the light of our humanity in favor of unconscious, animal existence; "sin is, in its essence, a renunciation of the truth" (Ratzinger, 1995, 71). On another level, sin is a normalization and acceptance of the collective ontological damage caused by every past instance of renunciation of the truth (Ibid., 73) Error begets error.

The ultimate consequence of sin is exemplified in the Biblical story of Cain and Abel (Genesis 4), the first two sons of Adam and Eve. Abel, the younger brother of Cain, is manifestly favored by God, exemplifying an ideal of righteousness that Cain could not match (1 John 3:12). Driven by jealousy and resentment of Abel, Cain subsequently slays his brother. A more detailed interpretation is given in the Quran (Surah 5:27-31), suggesting that Abel was intrinsically steadfast in his aversion to murder even in self-defense, whereas Cain's "soul permitted him to murder his brother". On this account, the special relationship of Abel with God seems more fundamental than just being liked; it may amount to reflexive, ontological affinity-being true to the likeness of the human ideal personified as God. Following the murder of Abel, Cain's descendants progressively populate the Earth beside the descendants of Seth, the youngest son of Adam and Eve, whose descendant is Noah. In the time of Noah, God decides to wipe the existing mankind off the earth, seeing His creation as corrupted beyond redemption, except Noah, whom God saves as the template of future humanity. It is noteworthy that the punitive annihilation was represented as a great flood consuming all living things except those accommodated on Noah's Ark. Symbolism of the flood suggest a return of all antagonistic beings to the undifferentiated common source, the unconscious sea, re-establishing the essential ontological unity corrupted by sin begetting sin since the murder of Abel. Cain's act of devaluing the existence of just one human being, a member of his own kin, has implicitly devalued all of humankind, thus initiating the process of annihilation of 'the world as we know it'. The said story arguably reveals social reflexivity as the ontological condition of human existence; we can preserve the integrity of our existence, stay true to the kind, only in virtue of continuously affirming the value of humanity in every instance of its manifestation. This ontological condition is later crystallized in the Golden Rule, "Love your neighbor as yourself" (Leviticus 19:18), and fully universalized in Jesus' pronouncement: "Love your enemies" (Matthew 5:44; Luke 6:27). Transgression against the constitutive conditions of conscious agency is possible, but every such transgression diminishes our existence as beings of the human kind (Kowalik, 2019).

"In everything that they do, they constitute themselves. Therefore they themselves (...) are always present as their standard, and when they reject this standard they deceive themselves. They do not free themselves, but place themselves in opposition to the truth. And that means that they are destroying themselves and the world" (Ratzinger, 1995, 61).

This kind of ontological liability or 'guilt' implies that certain actions have the same effect irrespective of their rational or moral justification, are not neutralized by self-defense, political rights, authority or good intentions, but damage us nonetheless, no matter what the circumstances. "Thou shalt not kill" is arguably a prime example of ontological liability that diminishes our existence even if we must kill to survive. As such, ontological wrongs entail an absolute liability requiring a special attitude, not one that only hopes that killing in self-defense will not be necessary, nor one that allows oneself to be killed (what would also arguably be an ontological wrong) but a proactive, rational effort to prevent absolute wrongs such as killing other humans from arising in the first place. Apart from any deeper metaphysical significance, the attitude of compassion, humility, rational consideration of the interests of others, or simply Good Faith, is a strategy geared for morally imperfect beings to be able to achieve that end. To be kind to others is a reflexive way of being 'true to kind', Imago Hominis reflecting Imago Dei.

\section{On Salvation}

According to Genesis, God presented Adam and Eve with a prohibition that was destined to be transgressed. Perhaps this apparent contradiction is the key to understanding the problem of evil and all the seemingly unloving, outrageous or violent commands that a genuinely 'loving' God would surely not unironically inflict on the humankind. One plausible theory of salvation is that God, the personified ideal of conscious agency made Sacred, may genuinely 
tempt us to do wrong so that we may apply Logos on our own authority as rational agents, out of our own free will, to make the right choice irrespective of any external authority; only then we are truly 'saved', when we have internalized the principle of good and evil to the point that we merge with the moral essence of God and thereby fully transcend our animality.

The ultimate test of our moral essence can perhaps be revealed only when we believe that God is dead, when there is no God, when no one is watching, when we believe that there will be no judgment or metaphysical consequence to our actions. If we are indeed imbued with the correct understanding of the principle of existence then we ought to able to make the right choice no matter who commands us to do otherwise. I suggest that the premise of Christ 'dying for our sins' should be understood as 'God died so that we may sin, with impunity', because only when everything is permitted we will find out who we really are, to what levels of depravity we are willing to stoop, or raise above. Only absolute moral freedom can reveal our moral essence, which is a cumulative effect of all our thoughts and actions, and this in turn implies that secularism and atheism could be a way of realizing 'the last judgment'. Through our actions we judge ourselves.

When we indulge the Human within us, the Human grows, the Animal fades; when we indulge the Animal within us, the Animal grows, the Human fades, which is to say, our rational agency, Logos, Imago Dei, is progressively extinguished. When we become aware of the actions that obscure the truth and propagate ontological error, provided that our true nature is indeed to value truth over error, only then we can feel genuine regret, which is perhaps to say, we can genuinely repent. In that moment, the moment of repentance, we ascend to become judges of ourselves according to the highest ideal and thus simultaneously transcend our wrongdoings and the state of being a wrongdoer; we metaphysically become what we 'ought to be': Imago Dei. It is then not the judgment that is frightening but its hypothetical absence, the indefinite deferral of judgment until there is nothing left in us that is worth saving, nothing Sacred. On this hypothetical account, the world is imbued with ontological justice: the inhuman things we do dehumanize us, turn us into animals and ultimately to stone.

\section{Conclusion}

Transcendental theology posits that the meaning of religion is encoded symbolically, rather than expressed literally. Characterization of a text as religious scripture, as the Revelation of God's will, is already symbolic; it presupposes a moral, epistemic and spiritual commitments that go beyond acceptance of any material facts. Religion is intrinsically symbolic. Transcendental theology is nevertheless compatible with the scripture being also literally true and with God's autonomous existence in the classical-realist sense of the term without presupposing it, but focuses on the aspect of God's being that is manifested in or for the human mind. There is logical space, even logical necessity, for mind dependent but still necessary truths about being, ontological truths that are essential to consciousness, presupposed by consciousness of being. The symbolic, insofar as it signifies the essential properties and presuppositions of being human, is the most objective interpretational form we have access to, the most fundamental real. The pursuit of this essential symbolism is then the strongest form of realism. The transcendental view of religion is therefore a form of essentialist realism as opposed to naive realism (without negating it); a pursuit of the essence of conscious being as a mode of God's existence. To discover the full extent of the normative implications that can be derived from what we intrinsically have in common is a task for the future of philosophy of religion; perhaps a unified theory of inter-faith normativity.

\section{References}

Altizer, Thomas. (2003). Godhead and the Nothing. State University of New York Press, New York.

Apel, Karl-Otto. (1996). Selected Essays: Ethics and the Theory of Rationality. Atlantic Highlands: Humanities Press International.

Aristotle. (1984). The Complete Works of Aristotle. Princeton: Princeton University Press.

Danker, Frederick, W. (2000). A Greek-English lexicon of the New Testament and other early Christian Literature. The University of Chicago Press, Chicago.

Eliade, Mircea. (1978). A History of Religious Ideas (1): From the Stone Age to the Eleusinian Mysteries. The University of Chicago Press, Chicago. 
Habermas, Jürgen. (2003). The Future of Human Nature. Polity Press, Cambridge.

Hay, David, M. (1989). Pistis as "Ground for Faith" in Hellenized Judaism and Paul. Journal of Biblical Literature, 461-76.

Kowalik, M. (2020). Ontological-Transcendental Defence of Metanormative Realism. Philosophia, 48, $573-586$. https://doi.org/10.1007/s11406-019-00149-6

Liddell, Henry George., and Robert, Scott. (1940). A Greek-English Lexicon. Clarendon Press, Oxford.

Nagel, Thomas. (1974). What Is It Like to Be a Bat? The Philosophical Review, 435-450.

Ratzinger, Joseph A. (1995). In the Begiunning... Michigan: William B. Eerdmans Publishing Co.

Ratzinger, Joseph A. (2006). Aula Magna of the University of Regensburg. September 12.

Strawson, Galen. (2013). 'Self-intimation'. Phenomenology and the Cognitive Sciences, 1-31.

Tillich, Paul. (1959). Theology of Culture. Oxford University Press, Oxford.

Tillich, Paul. (1967). A History of Christian Thought. Simon \& Schuster, New York.

Cite this article as: Michael Kowalik (2022). Transcend ental Theology for N on-Believers. A frican J ou rnal of H umanities and Social Sciences, 2(1), 30-37. doi: 10.51483/ AFJHSS.2.1.2022.30-37. 